\title{
Complementing Educational Services for Adults as a Factor in the Preservation of the CIS Educational Space
}

\author{
Marina llakavichus ${ }^{1, a}$, Marina Yakushkina ${ }^{1, b *}$ \\ 1 Institute of Education Management of the Russian Academy of Education, 105062, 16 \\ Zhukovskogo str., Moscow, Russia \\ amarinaorlova_99@inbox.ru, bvosp_spbgu@mail.ru \\ ${ }^{*}$ Corresponding author
}

\begin{abstract}
Keywords: adult education, non-formal education, educational space of the CIS, educational consulting, educational services
\end{abstract}

\begin{abstract}
The paper focuses in the need to update the resource of educational services for adults operating in the CIS member states, based on the principle of complementarity. The concept of "educational service" is analyzed. The problem of coordinating counseling services for adults in the Commonwealth countries is considered. The experience of consulting in this area, the prospects for its development in terms of solving the problem of preserving the educational space of the CIS are also described.
\end{abstract}

\section{Introduction}

Continuity and openness are the two system-forming parameters of modern education. A person under conditions of constant changes has to build his own adaptation strategy, in which new knowledge is the main activity. This activity is designed to support new resources, their novelty is due to technological changes in recent years. The digital environment today is a factor transforming educational reality. The scale of open free online courses is already difficult to quantify. In addition, there is a sector of personalized services, the popularity of which consists precisely in the personal meeting of the student with the master. The best traditions of Soviet education developing today in the CIS educational space are the basis on which the educational systems of independent states are built. Each of them tries to preserve something valuable which was formed in the previous historical period. A vivid example is Belarus from the forefront (not only in the CIS, but also in the EU) by the vocational education system, which roots go back to the Soviet past. And so each of the CIS countries has its own "peculiarity". And in the sea of proposals and requests that has been formed and is constantly growing, one needs a navigator being professionally functioning.

The subject of our research interest is consulting as a qualified informational support in building an adult's individual educational path. In adult education, it is aimed at analysing, personalized prediction and satisfying the educational needs of those in need. We can state the slow but constant development of educational consulting in the last 5 years. It is connected with the understanding of the effectiveness of integration of different environments (information, cultural, natural, etc.) in the matter of socio-economic development in general and personal development in particular. In this perspective, education can become the basis of a multinational community of the CIS and each of its member states.

\section{Main part}

The specifics of continuing education at the present stage.

As of today, the paradigm of learning in traditional educational organizations has changed: both learning, work, and cultural and leisure activities are ongoing, parallel, and interconnected. Traditional societies are transformed into learning ones. In the traditional society that lives on the principle of "education for all life," learning takes place mainly within the walls of educational institutions in the formal education system. In the learning society, training and work activities are carried out parallel to each other being interconnected in all social institutions. The results of education are mutually complementary, no matter what kind of continuing education they have achieved. Non-formal education is of particular importance in this context. It differs from all others by such characteristics as a poorly structured process, its maximum orientation to audience requests (from content to venue), high motivation of participants determined by 
these conditions, and the optional issuance of the established sample certificate. First of all, in the field of non-formal education, the development of educational services for adults is taking place, which is driven by competition.

\section{Market and educational needs in the field of adult education services.}

Over the past quarter century, educational services are one of the most dynamically changing elements of the socio-economic sphere [1]. The concept of "educational service" has not been fully formed, but it is fixed in international and Russian classifiers. Karnaukhova and Krakovskaya believe that the educational service is an intellectual one [3]. A new integrative subject of activity is the person as a subject of labor and a subject of creativity. An educational service is aimed at shaping the ownership of each business subject by means of survival: by adapting to the changing characteristics of the environment (characteristic of nature) adaptive management - and changing the environment to fit its own relative uniqueness and immutability (characteristic of society as a focused education) - constructive self-management. It seems appropriate to consider it a necessary component of an educational service of an adaptive self-management technology as a method of situational resource management of a business subject. This is self-management of savings, conservation, rational use of the hypersubject resource. Another component is the technologies of forming an educational environment or space, a living environment (including the internal one), situational behavior, tolerance, openness, intersubjectivity, career, readiness for learning, creative attitude, etc. An educational service includes the following: organization of educational activities of subjects of all types and levels of education, satisfying the need for mastering universal knowledge, acquiring skills in education, forming situational reactions of a subject being ready for productive activities, preserving the achieved knowledge for posterity; creating the most comfortable conditions for personal development, personal and social implementation of performers and customers' who are also co-performers.

Marketing approach in the study of educational services (O. V. Mitasova, A. A. Tancev, N. A. Platonova) implies the need to analyze and take into account consumer values of educational services, their relevance in the market, competitiveness. A pedagogical approach is associated with studying the phenomenon based on analyzing the results of its influence on the goals and objectives of the educational process (N. I. Bashmakova, I. I. Melnikov, O. E. Lebedev).

\section{Consulting activities as a promising area of joint efforts in the CIS space.}

Analyzing organization's experiences of this type of activity allows one to select several realizable forms. In the first place, it is various Internet resources in the era of digitalization. Search engines already support this direction, and the development follows the path of territorial detailing (not only a country, a city, but even a microdistrict). In second place are the employment services, labor migration. Further go higher educational institutions. The development of agencies began. An example of best practices in creating consulting services in the field of educational services can serve Belarus. Both citizens of the Commonwealth countries and the EU representatives use services functioning in Belarus. Russia and Uzbekistan follow the same path. In this direction, Russia solves the problem of building a system of continuous education, expanding the range of proposals on the parameter of the content of education. An example is the archaeological and art history and restoration programs of the Russian Museum of Ethnography. Uzbekistan solves the problem of preparing civilized labor migration, gathering the necessary specialists in one territorial place. The actively developing self-organizing educational communities of general cultural orientation, which unite citizens of different countries of the Commonwealth, require special attention.

In this regard, it seems promising to create a consulting service, whose divisions can accumulate the necessary information on the effective services of various subject areas collected in the entire educational space of the CIS. They can undertake the compilation of typed individual educational routes - unique templates for further individual work. Studies have shown that public organizations, social centers of the modern format, can perform a similar function [2]. Separately, we would like to note the need to respect not only the principle of complementarity in the field of representation of different CIS member states in the data bank, but also the complementarity of the two main areas of adult education - professional and general-cultural. In this case, the CIS educational space will maintain a culture-like orientation. 


\section{Conclusion}

The modern CIS educational space, broadcasting a variety of information, puts a potential learner in front of a choice, the effectiveness of which is directly dependent on professional assistance. There is a problem of evaluating information, evaluating available services offered to adults within the countries of the Commonwealth, and services of the information and educational space of the CIS. This task can be performed by a joint consulting service, which elements are already actively functioning in each of the CIS member states.

\section{Acknowledgments}

The article was prepared within the framework of the implementation of the state assignment on the theme "Development of national-regional educational spaces in the context of the formation of an interstate educational policy of the CIS member states 27.942.2017/БЧ"

\section{References}

[1] Avanesova, G. A. (2004). Service activities. Moscow, Russia: Aspect Press.

[2] Ilakavichus, M. R., Yakushkina, M. S., \& Shaposhnikova, T. D. (2017). Pedagogical potential of a modern social center: development management: a collective monograph. St. Petersburg, Russia: Renome.

[3] Karnaukhova, V. A., \& Krakovskaya, T. A. (2006). Service activities. (Moscow, Russia: Mart Publishing Center. 